\title{
UNCERTAINTY AND INVESTMENT: AN EMPIRICAL INVESTIGATION USING DATA ON ANALYSTS' PROFITS FORECASTS
}

\author{
Stephen R. Bond \\ Nuffield College, Oxford and Institute for Fiscal Studies
}

Jason G. Cummins

Division of Research and Statistics, Federal Reserve Board

March 15, 2004

We thank Nick Bloom, Darrel Cohen, Janice Eberly, Charlie Himmelberg, Christina Romer, David Romer, Anna Scherbina, Murtaza Syed and John Van Reenen for helpful discussions, and participants in seminars at Bergamo, Columbia, Federal Reserve Board, Hunter, NBER, Northwestern, and Oxford for useful comments. Financial support from the ESRC Centre for Public Policy at the Institute for Fiscal Studies is gratefully acknowledged. The views presented are solely those of the authors and do not necessarily represent those of the Board of Governors of the Federal Reserve System or its staff members. 


\begin{abstract}
$\underline{\text { Abstract }}$
We investigate the empirical relationship between company investment and measures of uncertainty, controlling for the effect of expected future profitability on current investment decisions. We consider three measures of uncertainty derived from (1) the volatility in the firm's stock returns; (2) disagreement among securities analysts in their forecasts of the firm's future profits; and (3) the variance of forecast errors in analysts' forecasts of the firm's future profits. We consider two controls for expected profitability: (1) a standard measure of Brainard-Tobin's $q$ constructed from the firm's stock market valuation; and (2) an alternative measure of the $q$ ratio constructed from discounted forecasts of the firm's future profits.

Our sample consists of publicly-traded U.S. companies that were tracked by two or more securities analysts for at least four consecutive years between 1982 and 1999. The results show that all three measures of uncertainty are positively correlated and appear to pick up underlying movements in uncertainty. When we consider these measures individually, we find a significantly negative long-run effect of higher uncertainty on capital accumulation, which is robust to the inclusion of either of our controls for expected profitability. When we consider our uncertainty measures jointly, we find that the level of disagreement among analysts provides the most informative indicator for identifying this long-run effect of uncertainty on capital accumulation. In addition, we find a significantly negative short-run interaction term between share price volatility and current sales growth, consistent with the idea that investment will respond less to a given demand shock at higher levels of uncertainty. These effects of uncertainty on investment are shown to be quantitatively as well as statistically significant.
\end{abstract}




\section{$\underline{1 . \text { Introduction }}$}

The sign and magnitude of the effect of uncertainty on investment has long been debated in the academic research literature and in public policy circles. How sensitive are investment levels, for example, to stability or instability in the macroeconomic environment? ${ }^{1}$ Although our empirical approach is not sufficiently granular to isolate the effects of a particular macroeconomic shock, our results suggest that increased uncertainty appreciably reduces investment in both the short run and the long run.

Theoretical analyses have suggested a variety of mechanisms through which uncertainty may influence investment decisions. Holders of risky assets require compensation for bearing those risks, so there will be a risk premium component in the required rate of return for investment projects with uncertain outcomes. Finance theory has emphasized that portfolio diversification can substantially reduce an individual's exposure to the risk associated with any particular asset. Hence, the relevant risk premium for firms owned by diversified shareholders should depend not on the variability of the firm's own returns but rather on the covariance between the firm's returns and the returns available on a wider portfolio of assets, as, for example, in the Capital Asset Pricing Model. Nevertheless, uncertainty about the firm's own future prospects may be more important than the CAPM suggests in settings where managers influence investment decisions and cannot fully diversify their exposure to idiosyncratic risk - perhaps for incentive reasons, or because they have invested in firm-specific human capital. ${ }^{2}$

Hartman (1972) and Abel (1983) emphasized a different mechanism that could rationalize a positive effect of higher uncertainty on investment. The basic idea in those models is that expected profits may be a convex function of future prices for the firm's

\footnotetext{
${ }^{1}$ For example, according to the Economic Report of the President (2004), "[The] tragic terrorist attacks of September 11, 2001, the corporate governance and accounting scandals of 2002, and the geopolitical tensions surrounding the war with Iraq in 2003 ...contributed to a climate of uncertainty that weighed on household and business confidence and thereby affected spending decisions." (p. 37)

${ }^{2}$ For example, incentive contracts in Himmelberg, Hubbard and Love's (2002) model prevent managers from diversifying, in which case firm investment depends on idiosyncratic risk.
} 
output. Suppose there is a mean-preserving spread in the distribution of future prices, so that the expected future price remains unchanged but more probability weight is attached to prices that are both very high and very low relative to this unchanged mean. If profits are a convex function of the output price, this will increase the expected level of future profits. If the risk premium is given or responds sufficiently little to the increase in uncertainty about the firm's future product price, this increase in the expected level of future profits will increase the range of possible investment projects with positive net present values, and so lead the firm to undertake additional investment.

Abel (1983) showed that this mechanism operates in Hayashi's (1982) $Q$ model of investment, in which there is perfect competition in all markets, constant returns to scale, and costs of adjusting the capital stock that are strictly convex in the level of investment. Caballero (1991) noted that this conclusion is sensitive to the assumptions of perfect competition and constant returns to scale, which make the firm's net revenue homogeneous of degree one in the scale of its operations. The convexity of the relationship between profits and output price can be weakened and eventually overturned by introducing a sufficient degree of either imperfect competition or decreasing returns to scale into the model. The impact of price uncertainty on investment may therefore be positive or negative, depending on assumptions about the market environment and technology. Complicating matters further still, empirical specifications cannot identify the sign of the effect of uncertainty in this class of models because uncertainty operates through the level of expected profitability. Hence, there would be no role for uncertainty in an empirical model that controlled adequately for the effect of expected future profitability on current investment decisions. In Hayashi's $Q$ model, for example, any uncertainty effect is summarized by the average $q$ ratio, which is a sufficient statistic for investment in his model.

More recent theoretical analyses have focused on the effects of "real options." In these models, the option to delay investment until more information has accumulated may become more valuable at higher levels of uncertainty. ${ }^{3}$ Interestingly, this option to delay investment is valuable only when both: (1) the net revenue function is not linearly

\footnotetext{
${ }^{3}$ See, for example, Dixit and Pindyck (1994) and Caballero (1999).
} 
homogeneous, for example due to imperfect competition or decreasing returns to scale; and (2) adjustment costs are not strictly convex in investment, for example due to full or partial irreversibility, or to a fixed component of adjustment costs. Hence, these real options effects are absent in the traditional $Q$ model.

When real options are valuable, the implications for the relationship between uncertainty and investment are quite subtle and often misunderstood. At higher levels of uncertainty, the firm has a greater incentive to wait until it has more information before committing to an investment decision. This incentive makes the firm's investment policy more cautious, or less likely to respond to a given demand shock. However, as stressed by Abel and Eberly (1999) and Caballero (1999), the effect of higher uncertainty on the average level of the capital stock in the long run is theoretically ambiguous. Although firms will invest less in response to a positive demand shock, they will also be stuck with more capital than they would like following a negative demand shock. Depending on which of these forces dominates, firms may operate with higher or lower capital stocks under conditions of higher uncertainty. As noted by Bloom, Bond and Van Reenen (2001), the more robust prediction of real options models is that the speed of adjustment of the capital stock should be slower at higher levels of uncertainty. Thus, the principal effect of real options may be on short-run investment dynamics, rather than on long-run capital accumulation.

As this brief review indicates, the theoretical literature on investment and uncertainty leaves open both the sign and the persistence of any relationship between uncertainty and capital accumulation. Empirical evidence is therefore required to address these questions, as well as to quantify the magnitude of any short- or long-run effects of uncertainty on investment. However, empirical work in this area must address two primary challenges: (1) to find operational counterparts to the concepts of uncertainty considered in theoretical analyses; (2) to control for other relevant influences on investment behavior, notably the role of current expectations of future profitability.

The importance of the first challenge is self-evident. To test the null hypothesis that uncertainty has no effect on investment and to quantify the relationship, we require a measure of uncertainty that is either accurate or at least measured with a type of error for 
which the errors-in-variables bias in the estimated relationship can be easily corrected. The second challenge is more subtle, but no less important. The obvious practical hurdle is that measured uncertainty may plausibly proxy for other relevant but omitted variables.

Consider, for example, the airline industry in the wake of September 11, 2001. Aircraft investment may have fallen for at least two distinct, but hard to disentangle, reasons. First, there was a downward revision of forecasts of future demand for air transportation. Second, there was an increase in the uncertainty associated with these forecasts. Without further analysis it would be difficult to say which of these effects was more important. More generally, we may suspect that higher uncertainty could be associated with greater pessimism about the level of expected future profitability. ${ }^{4}$ Unless we control carefully for the effect of expected profitability on current investment, effects which are really due to changes in the level of expected future returns may erroneously be attributed to uncertainty. Note that the distinction between these two channels is potentially important for policy formulation: if the aim is to increase the level of investment, will anything be achieved by a policy that seeks to reduce uncertainty by pursuing stability, or should the emphasis rather be on policies that operate by raising expected future returns?

In this paper, we aim to make a contribution by confronting both these empirical challenges, as well as stressing the importance of distinguishing between short-run effects of uncertainty on investment dynamics and long-run effects of uncertainty on capital accumulation. The novel aspect of our approach in this context is to make use of data on forecasts of future profits for individual companies that were issued historically by professional securities analysts. ${ }^{5}$ These data allow us to construct two indicators of the level of uncertainty facing a particular firm at a particular time, one based on the disagreement or dispersion in the profits forecasts issued by different analysts for that

\footnotetext{
${ }^{4}$ Commentators frequently suggest this association between the mean and the variance of the distribution of future demand or future profits. For example, commenting on the Confederation of British Industry's August 2002 Regional Trends Survey, Doug Godden, Head of Economic Analysis at the CBI, observed that "with so many new risks and uncertainties, output expectations have been scaled back in the majority of regions" (http://www.cbi.org.uk).

${ }^{5}$ Earlier papers that use data on analysts forecasts to study company investment include Cummins, Hassett and Oliner (1999), Bond and Cummins (2000, 2001), Bond, Klemm, Newton-Smith, Syed and Vlieghe (2002) and Abel and Eberly (2002a).
} 
firm at that time, and one based on the variance of the forecast errors made by analysts forecasting profits for that firm in the recent past. We compare these variables with a more standard measure of uncertainty based on the high frequency volatility in the firm's stock returns, which was introduced into the empirical investment literature by Leahy and Whited (1996) and also used by, for example, Bloom, Bond and Van Reenen (2001).

An obvious concern with measures of uncertainty based on share price volatility is that they may be affected by excess volatility or "irrational exuberance" in the stock market, a concern which has been highlighted by previous research on the relationship between stock market valuations, expected profits and company investment. ${ }^{6}$ Related to this, the availability of data on profits forecasts allows us to construct an alternative control for the influence of expected future profitability in our empirical investment equations. Several of the papers cited in footnote 4 above have shown that using a simple valuation model to transform these forecasts of future profits into an estimate of the firm's 'fundamental' value provides a measure of the average $q$ ratio that is far more informative about company investment than the standard Brainard-Tobin's $q$ measure constructed using the firm's stock market valuation. By considering both measures of average $q$ in this investigation, we provide more robust controls for the effects of expected future profitability than previous empirical studies, and so obtain more appropriate tests of the null hypothesis that variation in the level of uncertainty has no effect on company investment beyond that which is summarized in current expectations of future profits.

The remainder of the paper is organized as follows. Section 2 discusses our econometric investment equations and relates these to the effects of uncertainty predicted by different theoretical approaches. Section 3 discusses our data and our empirical measures of uncertainty and average $q$. Section 4 presents our main empirical findings and illustrates the quantitative importance of the effects of uncertainty on company investment. Section 5 concludes with some qualifications and suggestions for further research.

\footnotetext{
${ }^{6}$ See, for example, Shiller $(1981,2000)$ and Bond and Cummins (2001).
} 


\section{Empirical investment equations}

We estimate empirical investment equations with the general form

$$
\left(\frac{I}{K}\right)_{t}=\alpha+\beta\left(q_{t}-1\right)+\gamma \sigma_{t}+\theta \Delta y_{t}+\phi\left(\sigma_{t} * \Delta y_{t}\right)+\varepsilon_{t}
$$

where $I_{t}$ is gross investment in period $t, K_{t}$ is the net capital stock at the end of period $t, q_{t}$ is a measure of average $q, \sigma_{\mathrm{t}}$ is a measure of uncertainty, $\Delta y_{t}$ is the growth rate of real sales and $\varepsilon_{\mathrm{t}}$ is an error term. Abstracting from the presence of debt and taxes-which are both accounted for in our empirical work-our measures of average $q$ have the form

$$
q_{t}=\frac{V_{t}}{\kappa_{t}}
$$

where $V_{t}$ is a measure of the fundamental value of the firm, defined as the present value of the expected stream of future net cash distributions to its shareholders, at the start of period $t$; and $\kappa_{t}$ is the replacement cost at the start of period $t$ of the capital stock that the firm inherits from the previous period. ${ }^{7}$

To interpret equation (1), notice that under the null hypothesis $\gamma=\theta=\phi=0$ it reduces to a version of the traditional $Q$ model in which the average $q$ ratio is a sufficient statistic for the gross investment rate. This specification would be correct if firms choose investment in a homogeneous capital good to maximize their fundamental value (i.e., the present value of the expected stream of future net cash distributions to their shareholders), taking all prices as given, and having both constant returns to scale

\footnotetext{
${ }^{7}$ More precisely, letting $p_{t}^{K} K_{t}$ denote the replacement cost of the firm's capital stock at the end of period $t$, and assuming the standard equation of motion for this capital stock:

$$
p_{t}^{K} K_{t}=(1-\delta)\left(p_{t-1}^{K} K_{t-1}\right)\left(p_{t}^{K} / p_{t-1}^{K}\right)+p_{t}^{K} I_{t}
$$
}

where $p_{t}^{K}$ is the price of capital goods in period $t$ and $\delta$ is the rate of depreciation, then $\kappa_{t}=p_{t}^{K}(1-\delta) K_{t-1}=p_{t}^{K}\left(K_{t}-I_{t}\right)$. 
technologies and strictly convex costs of adjusting their capital stocks. ${ }^{8}$ In this case, the parameter $\beta$ is inversely related to the importance of marginal adjustment costs and directly related to the speed at which firms adjust their capital stocks in response to deviations between average $q$ and the value of unity that would be chosen in the absence of adjustment costs and taxes; and the error term reflects either additive shocks to marginal adjustment costs or additive errors in our measure of the average $q$ ratio.

The inclusion of the additional terms in the empirical models we estimate thus tests the null hypothesis that our measure of average $q$ is a sufficient statistic for company investment rates. We stress that a rejection of this null hypothesis does not necessarily imply a rejection of the underlying $Q$ theory, essentially because there may be measurement errors in the available proxies for average $q$ that are correlated with either the uncertainty or sales growth variables. We return to this important caveat in section 4.4, after describing our empirical results. However, for practical purposes this limitation may not be critical because significant coefficients on the uncertainty terms still indicate that company investment is related to these indicators of uncertainty, holding constant either observable expectations of future profitability or the firm's stock market valuation.

Two simple measures can be calculated easily from the parameters of the estimated models and used to illustrate the magnitude of the estimated effects of uncertainty on investment. The first is a short-run effect, or the partial elasticity of the investment rate with respect to the measure of uncertainty, holding constant both average $q$ and real sales growth:

$$
\left.\frac{\partial(I / K)}{\partial \sigma} \cdot \frac{\sigma}{(I / K)}\right|_{q, \Delta y}=\frac{(\gamma+\phi \Delta y) \sigma}{I / K} .
$$

The second is a long-run effect, or the partial elasticity of the capital stock with respect to the measure of uncertainty, holding constant the value of the firm. Appendix A shows

\footnotetext{
${ }^{8}$ Linearity of the investment- $q$ relationship further requires adjustment costs that are quadratic. Interested readers are referred to Bond and Cummins (2001) for details of the timing and functional form assumptions that result in our particular null specification.
} 
that if we consider a steady state in which both the capital stock and real sales grow at rate $g$, this steady-state partial elasticity has the form:

$$
\left.\frac{\partial \kappa}{\partial \sigma} \cdot \frac{\sigma}{\kappa}\right|_{V}=\left(\frac{V}{\kappa}\right)\left\{\frac{\left(\frac{\gamma+\phi g}{\beta}\right) \sigma}{\left[1-\left(\frac{\gamma+\phi g}{\beta}\right) \sigma-\left(\frac{\theta}{\beta}\right) g\right]^{2}}\right\} .
$$

Given the estimated parameters $\beta, \gamma, \theta$ and $\phi$, these partial elasticities can be evaluated, for example at the sample means of the investment rates, $q$ ratios, uncertainty measures and sales growth. We consider the short- and long-run elasticities in order to evaluate whether the estimated effects of the uncertainty terms in our empirical models are trivial or sufficiently large to motivate further research. In addition, we can also use these elasticities to see whether the predictions of our empirical model line up with those from leading theoretical models - keeping in mind, of course, that we are not estimating or testing a structural alternative to the basic $Q$ model in which uncertainty measures would influence behavior conditional on average $q$.

Notice first that in a stationary environment $(g=0)$, the long-run effect would depend only on the parameter $\gamma$ on the linear uncertainty term, and not on the parameter $\phi$ on the uncertainty-sales growth interaction term. More importantly, an empirical model with only a single, linear uncertainty term would impose that the short- and long-run effects are determined by the single parameter on this variable. This seems unduly restrictive for testing purposes, since a number of authors have stressed that in the real options approach, there may be significant short-run effects of uncertainty on investment dynamics without necessarily any long-run relationship between uncertainty and capital intensity. Our empirical specification allows this pattern - for small $g$, this would correspond simply to a zero coefficient on the linear uncertainty term but not on the interaction term between sales growth and uncertainty. This interaction term is of particular interest, as Bloom, Bond and Van Reenen (2001) have shown that a weaker impact effect of demand shocks on investment at higher levels of (demand) uncertainty is a prediction of one class of real options models that is robust to aggregation across investment decisions in multiple capital goods; and significant effects of this kind have 
been reported in previous empirical studies. ${ }^{9}$ In addition, more flexible patterns of shortand long-run effects can be introduced by adding lagged uncertainty terms to the model, or by considering further interactions, for example between uncertainty and average $q$ measures. We also explore both these possibilities in our empirical investigation.

Finally, we should comment on why we adopt an exploratory empirical approach in this investigation, rather than attempting to estimate a richer structural specification that would allow for effects of uncertainty on investment holding constant expected future profitability or stock market valuations. Put simply, so far as we know, there is no operational structural model using the real options approach that could be estimated directly. Abel and Eberly (2002a) derive a non-linear structural relationship between investment rates and average $q$ in the presence of irreversibility, but only under conditions of perfect competition and constant returns to scale which rule out the real options effects. A second reason is that, to obtain a convincing specification for company-level data, a structural approach would need to take seriously aggregation of investment decisions over the multiple types of capital goods, production plants and subsidiaries that are combined in the capital expenditure data found in company accounts. Given the obvious complexity of these tasks, we believe that a simpler, more descriptive, empirical approach, despite its manifest limitations, can still provide useful evidence to inform policy discussions, and may stimulate further research toward a more satisfactory empirical framework for analyzing these issues.

\section{Data and empirical measures}

\section{$\underline{3.1 \text { Basic data sources }}$}

Our dataset combines firm-level information from several sources. The accounting data are from Compustat. The data on expected earnings are from $\mathrm{I} / \mathrm{B} / \mathrm{E} / \mathrm{S}$ and some financial data are from CRSP. In this section, we briefly review the

\footnotetext{
${ }^{9}$ See Guiso and Parigi (1999) and Bloom, Bond and Van Reenen (2001).
} 
construction of key variables and then we describe in detail the measures of uncertainty and average $q$. For an exhaustive description of our dataset, we refer the interested reader to Bond and Cummins (2003) and www.insitesgroup.com/jason, a webpage that contains our programs and data.

The basic nonfinancial data on investment expenditures, capital stocks, sales, profits and cash flow are obtained from Compustat. We adjust book values of the net capital stock to replacement cost estimates using a standard perpetual inventory procedure, and we adjust nominal sales and cash flow to real measures using sectoral price indices available from the Bureau of Economic Analysis. Stock market data on equity capitalization and daily stock returns are from CRSP.

Data on analysts' profits forecasts are kindly made available to us by $\mathrm{I} / \mathrm{B} / \mathrm{E} / \mathrm{S}$ International Inc. I/B/E/S reports forecasts only from analysts who meet a set of criteria designed to ensure that they are well informed about the business situation of individual companies. The forecasts we use were issued early in the current-year accounting period, and comprise forecasts of earnings per share for the current year and for the following year, as well as forecasts of the trend growth rate in earnings per share over a three- to five-year period, known as the long-term growth forecasts. I/B/E/S reports the (unweighted) mean of the analysts forecasts issued for a particular firm, known as the consensus forecast, as well as the standard deviation across these individual forecasts. We make use of both the mean and the standard deviation in our measures of expected profits and uncertainty, respectively. The measure of earnings corresponds to that agreed on by the majority of analysts tracking a particular firm. In broad terms, this definition corresponds to a measure of net profits after interest and taxes, and it removes a larger set of non-recurrent items than extraordinary items reported in published accounts.

In addition to the availability of accounting and stock market data, we require that firms were tracked by at least two securities analysts, who supplied timely profits forecasts to I/B/E/S for a minimum of four consecutive years between 1982 and 1999. This requirement likely introduces a sample selection bias, although to the extent that selection into the set of firms tracked by multiple analysts is determined by time-invariant characteristics, this should be controlled for by the inclusion of firm-specific fixed effects 
in our econometric specifications. Results for our basic average $q$ models are similar for this sample and for a larger sample of firms tracked by one or more analysts, used in our previous research; and results for models that include our dispersion or error variance measures of uncertainty remain similar when we consider smaller samples of firms that are tracked by a minimum of three or five securities analysts. After applying the twoanalyst requirement as well as standard screens to eliminate outliers, we end up with an unbalanced panel of 946 publicly-traded companies for estimation.

\section{$\underline{3.2 \text { Uncertainty measures }}$}

We construct three different indicators of uncertainty for an individual firm at a particular time. The first measure is a relatively standard one based on the high-frequency volatility in a firm's stock market valuation, introduced into the empirical literature on uncertainty and investment by Leahy and Whited (1996). If new information about future demand and costs leads to a marked reassessment of the firm's expected future profitability, it will be reflected in fluctuations in the firm's stock market valuation, provided there is a reasonable correspondence between stock market and 'fundamental' values.

The specific measure we use, denoted $V O L_{t}$, is the standard deviation of daily stock returns during the firm's current accounting period, based on the index of total stock market returns (net of share repurchases) reported by CRSP. An obvious concern with this kind of measure is that fluctuations in share prices may reflect changes in factors that are not perceived as relevant to investment decisions by the managers of firms, as may be the case when stock market valuations are influenced by factors other than the present value of expected future distributions to shareholders, such as bubbles or fads. Shiller's (1981) term for such behavior of share prices was excess volatility, and if actual share price volatility is dominated by such factors then tests using a stock-marketbased indicator may have little power to detect any effects of uncertainty on company investment. A different concern is that it is possible for future profits to be highly uncertain, in the sense that the distribution perceived at a particular point in time has a 
high variance, and yet for the expectation of future profits to be completely stable, if no relevant new information is revealed during a particular time interval.

To explore the robustness of empirical results based on this stock return volatility indicator of uncertainty, we make use of the data on analysts' profits forecasts to construct two alternative indicators. Neither is conceptually perfect or necessarily superior to the volatility measure. Rather, we may learn more about the nature of any relationship between uncertainty and company investment by considering a wider range of indicators.

One of the measures that we consider is based on the disagreement among different securities analysts forecasting future profits for the same firm at the same time. ${ }^{10}$ We certainly observe such disagreement in the $\mathrm{I} / \mathrm{B} / \mathrm{E} / \mathrm{S}$ data, and the degree of disagreement varies both across firms and, for a given firm, over time. In the limit, if the level of future profits for a particular firm was completely certain, it would be surprising if all analysts did not report this common figure as their forecast. Hence, it would be surprising if a low level of uncertainty about the level of future profits was not reflected in a low degree of disagreement among different analysts in their individual forecasts. It is less clear that a high level of uncertainty will necessarily be reflected in a high degree of disagreement among analysts. Differences in the forecasts issued by individual analysts may reflect differences in the information available to them, in the way they process this information, or in the objectives they are pursuing. ${ }^{11}$ It is clearly possible for the level of future profits to be highly uncertain, and yet to observe a set of analysts using

\footnotetext{
${ }^{10}$ In a similar vein, a number of studies have related disagreement among inflation forecasts to uncertainty about inflation. Indeed, Mankiw, Reis, and Wolfers (2003) have recently argued that disagreement about expected inflation may be a key to better understanding macroeconomic dynamics. However, Zarnowitz and Lambros (1987) caution that disagreement and uncertainty are distinct concepts, even though they turn out to be positively correlated in their sample of professional inflation forecasters. Hence, the disagreement among analysts in our sample should be thought of as a proxy for uncertainty. Even so, this limitation is not as serious as it may seem at first glance because our econometric approach explicitly allows for measurement error.

${ }^{11}$ There is no consensus explanation for analysts' behavior in the burgeoning literature about the properties of earnings expectations (for a recent survey see, e.g., Kothari 2001). Nevertheless, given the lambasting analysts have taken from the popular press in the past few years, it is worth noting that Keane and Runkle (1998) find no evidence that analysts profit forecasts deviate from rational expectations. Along similar lines, Lim (2001) argues that analysts have an incentive to issue overly optimistic forecasts in order to maintain access to company management. Nevertheless, he shows that analysts issue forecasts with minimum mean-squared error, as the benefit of greater information more than offsets the upward bias.
} 
similar information in a similar way, with similar objectives, arriving at a similar set of issued forecasts. Nevertheless, we would expect the tendency to be for more observed disagreement to be associated with more underlying uncertainty. For example, to the extent that differences in forecasts reflect differences in the way different analysts convert the same current information into forecasts of future profits, one possibility is that the survival of these different models is indicative of underlying uncertainty about the correct process generating future profits. Alternatively, to the extent that analysts issuing optimistic forecasts are pursuing marketing strategies more aggressively than others, a high degree of uncertainty about the actual level of future profits would seem to be a necessary condition for the survival of these strategies in equilibrium.

The particular measure of dispersion across individual analysts' earnings forecasts that we use, denoted DISP $P_{t}$, is the coefficient of variation in the forecasts of earnings per share for the current accounting period. A scale invariant measure is warranted because the variation across firms in the level of earnings per share reflects measurement in arbitrary, and economically meaningless, units. ${ }^{12}$ Since we observe only the mean and the standard deviation of the distribution, we are severely limited in the measures of relative dispersion we can compute. ${ }^{13}$ Practical considerations call for focusing on disagreement in the one-year-ahead forecasts; typically, we observe more analysts issuing forecasts for profits one year ahead than for longer time horizons. ${ }^{14}$

The final measure we consider is based on the variance of the errors made by securities analysts in forecasting the firm's profits in the recent past. The particular forecast error we use for this purpose is the difference between the consensus forecast,

\footnotetext{
${ }^{12}$ Notice that $\mathrm{VOL}_{t}$ is already scale invariant because it is constructed from stock market returns. Moreover, it would be nonsensical to use the coefficient of variation of $V O L_{t}$ as a measure of uncertainty because such a measure would be negative when annual stock market returns are negative, as is common.

${ }^{13}$ We obtain estimated coefficients with the same sign but with weaker statistical significance in our investment equations if we use the simple standard deviation in place of the coefficient of variation. We also checked that our coefficient of variation measure does not simply proxy for information in (1) the reciprocal of the mean earnings per share forecast, which could occur if the relationship between investment and expected profits were sufficiently non-linear; or in (2) the number of analysts tracking a particular firm, which is positively correlated with this measure of relative dispersion, but uninformative in our investment models once we condition on $\operatorname{DISP}_{t}$.

${ }^{14}$ Our results were qualitatively similar, but less precisely estimated, when we used the coefficient of variation for the two-year-ahead earnings per share forecasts.
} 
made at the start of the current accounting period, of earnings per share for that period, and the realization of that measure reported by $\mathrm{I} / \mathrm{B} / \mathrm{E} / \mathrm{S}$. In our empirical work, we use the squared value of that forecast error, denoted $E R R_{t}{ }^{15}$ Again, if there was very little uncertainty about the level of future profits, we would expect analysts to make very small forecast errors. Where we observe at least some analysts making large forecast errors, this could reflect the pursuit of objectives other than accurate forecasting, but a higher degree of uncertainty seems likely to be a permissive factor in the survival of such strategies.

There are two practical problems relating to $E R R_{t}$. First, the squared forecast error for a particular firm-year observation cannot be used to measure uncertainty by itself. We can get around this limitation, however, by exploiting the time dimension of our panel dataset. In particular, we can estimate the forecast error variance using repeated observations from the same firm. As an empirical matter, using too few observations would result in imprecise estimates of the variance, while using too many observations would produce limited time-series variation in the resulting measure for each firm, and runs the risk of erroneously imposing the continued relevance of past levels of uncertainty. We keep this trade-off implicit by including current and past realizations of the squared forecast errors as separate explanatory variables in our empirical investment equations, which can allow more weight to be given to more recent experience, without imposing any particular pattern to the weights. However, the small number of time-series observations available for many firms in our sample limits the flexibility we have, so we include two lags in practice. Second, the measure of earnings per share forecast by analysts may not correspond precisely to the basis on which results are subsequently reported, for example if the number of shares outstanding has changed in the intervening period. We use a measure of realized earnings per share reported by $\mathrm{I} / \mathrm{B} / \mathrm{E} / \mathrm{S}$ which is intended to adjust for such differences, although the scope for making these adjustments accurately is an unresolved issue.

\footnotetext{
${ }^{15}$ Note that $E R R_{t-1}$ is thus the most recent forecast error that has been observed at the start of period $t$.
} 


\section{$\underline{3.3 \text { Average } q \text { measures }}$}

We consider two controls for the average $q$ ratio in our null specifications, one constructed using the firm's stock market valuation in a standard way, and one in which a simple valuation model is used to obtain an alternative estimate of the value of the firm, based on the consensus forecasts at the start of the current accounting period for the firm's profits in that and subsequent periods. The standard measure is denoted $q_{t}^{E}$ and the alternative measure is denoted $\hat{q}_{t}$. Both measures incorporate identical adjustments for the presence of debt, financial assets and corporate taxes; details are provided on www.insitesgroup.com/jason.

The particular valuation model we use here is taken from Bond and Cummins (2001). Letting $\mathrm{E} \Pi_{t}$ denote the consensus forecast for earnings in period $t, \mathrm{E}_{t+l}$ denote the consensus forecast for earnings in period $t+1,{ }^{16}$ and $\mathrm{E} g_{t}$ the consensus forecast for the long-term trend growth rate of earnings, we estimate the firm's 'fundamental' value as

$$
\hat{V}_{t}=\mathrm{E} \Pi_{t}+\beta_{t} \mathrm{E} \Pi_{t+1}+\sum_{s=2}^{5} \beta_{t}^{s}\left(1+\mathrm{E} g_{t}\right)^{s-1} \mathrm{E} \Pi_{t}^{*}+T V C
$$

where $\mathrm{E} \Pi_{t}^{*}=\left(\mathrm{E} \Pi_{t}+\mathrm{E} \Pi_{t+1}\right) / 2$ is the average of the two earnings forecasts which we grow out over a five year horizon at rate $\mathrm{E} g_{t}, \beta_{t}$ is a discount factor using the nominal interest rate on US government bonds in year $t$ plus an $8 \%$ risk premium, and $T V C$ is a terminal value correction which imposes the assumption that earnings growth beyond year $t+5$ reverts to the overall historical average for our sample of companies, which is about $6 \%$. It should be stressed that our empirical results are not sensitive to the details of this particular calculation.

The motivation for considering this alternative measure of average $q$ is that previous studies have found a much stronger relationship between company investment and these discounted profits forecasts than has generally been found between company investment and the firm's stock market valuation. This fact is consistent with the

\footnotetext{
${ }^{16}$ Forecasts for earnings per share are converted to forecasts for the level of earnings by multiplying by the number of shares outstanding at the time the forecasts were made.
} 
possibility of significant bubbles, fads or factors other than the present discounted value of expected future profits influencing fluctuations in stock market valuations - which motivates our interest in measures of uncertainty other than share price volatilityalthough there may be other explanations for the same pattern. ${ }^{17}$ Here the objective is to obtain a more informative control for the influence of current expectations of future profitability on current investment decisions than can be achieved indirectly by using the firm's stock market valuation. By controlling for these observable forecasts of future profits, we reduce the risk that any estimated effects of our uncertainty variables are attributable to these uncertainty measures acting as proxies for the influence on investment of the mean rather than the variance of the distribution of future profits. This risk is clearly signaled by the models of Hartman (1972) and Abel (1983), which stress a causal link between (price) uncertainty and the expected level of future profits. More generally, we are concerned about a possible correlation between uncertainty and expected profitability, for example if periods of higher uncertainty tend to be associated with more pessimistic forecasts of future demand growth.

\section{$\underline{4 . ~ R e s u l t s ~}$}

\section{$\underline{4.1 \text { Behavior of uncertainty measures }}$}

Before turning to our econometric analysis, we explore graphically the key properties of our uncertainty measures. The three measures of uncertainty are positively correlated with each other but the fit is rather loose (figure 1). Each dot in the figure represents a single firm-year observation, and the OLS regression line describes the average relationship between the two variables. In the first panel, $V O L_{i t}$ and $D I S P_{i t}$ move together - the slope of the regression line is 0.1 with a standard error of 0.01 - but volatility often differs widely from dispersion as indicated by the low $R^{2}$ of 0.03 . In the middle panel, $V O L_{i t}$ and $E R R_{i t}$ are also positively correlated but the fit is appreciably

\footnotetext{
${ }^{17}$ Abel and Eberly (2002b) develop a model in which long and variable lags between technological advances and profitable investment opportunities help to explain the weak relationship between stock market valuations and current investment expenditures.
} 
worse compared with the first panel. In the final panel, the two analyst-based measures are more tightly linked with each other than with $V O L_{i t}$ the statistically significant slope coefficient is 0.74 but the $R^{2}$ is just 0.025 because there is a considerable mass of observations with big forecast errors and little dispersion. ${ }^{18}$ Taken together, these comparisons are reassuring: the positive covariance between the three variables suggests that our proxies, even though they suffer from measurement error, get at the underlying uncertainty that firms face.

A look at the time dimension of the panel reveals the business cycle variation in uncertainty and underscores two of our empirical challenges. In figure 2, we depict some sample statistics for the annual averages of $V O L_{t}$ and $D I S P_{t}{ }^{19}$ As can be seen in the top panel, stock market volatility in our sample peaks in the late 1990s and 1987 (as measured by either the mean or median), a pattern that matches the volatility of broadbased stock market indexes but is disconnected from the business cycle. Indeed, the readings in 1998 (Russian and Asian financial crises) and 1987 (stock market crash) illustrate one of our primary empirical challenges — namely, a stock-market-based measure of uncertainty may reflect excess volatility. By contrast, the annual average (or median) of the dispersion of analysts' forecasts (bottom panel) is inversely related to the business cycle. ${ }^{20}$ And, it is this link that highlights a second empirical challengenamely, it is important to control for fundamentals because higher uncertainty is associated with greater pessimism about expected profits. We confront both of these challenges in the econometric work that follows.

Finally, we need to pick some reasonable numbers in order to calibrate the shortand long-run impact of uncertainty. Coincidentally, it turns out that, for a given firm, a

\footnotetext{
${ }^{18}$ Since firm-year observations of $E R R_{i t}$ do not measure the variance of the forecast errors, we also looked at the cross-sectional (i.e., between-firm) relationships among our uncertainty variables. The variance of $E R R_{i}$ are positively correlated with $D I S P_{i}$-in fact, the between-firm relationship is somewhat tighter than pictured in figure 1 (final panel), which compared the total variation in the two variables. However, the variance of $E R R_{i}$ is uncorrelated with $V O L_{i}$ in the cross-sectional dimension of the panel.

${ }^{19}$ The annual average of analysts' forecast errors is not a good measure of uncertainty because we must exploit the panel structure of the data to estimate the variance of the forecast error.

${ }^{20}$ To be concrete, the OLS regression (1982-1999) of the real growth rate of business fixed investment (chain-weighted (2000) dollars) on the annual average of $D I S P_{t}$ yields a $t$-statistic equal to -3.2 for the slope coefficient. Similar exercises show that $D I S P_{t}$ is also significantly negatively correlated with broader measures of the business cycle like the growth rate of real GDP.
} 
$15 \%$ change in either $V O L_{t}$ or $D I S P_{t}$ is nearly one standard deviation from that variable's mean. ${ }^{21}$ Hence, large changes in uncertainty are relatively common.

\section{$\underline{4.2 \text { Econometric results }}$}

We estimate a range of empirical investment equations in first-differences, a transformation that removes unobserved firm-specific fixed effects that may be correlated with the explanatory variables. Year dummies are also included to control for unobserved time-specific effects. Both measures of $q_{i t}$ and the uncertainty terms are treated as endogenous variables in these investment equations. A common instrument set comprising lagged investment rates and cash flow- $(I / K)_{i, t-2},(I / K)_{i, t-3},(C F / K)_{i, t-2}$ and $(C F / K)_{i, t-3}$-is used to estimate all the specifications reported. ${ }^{22} \mathrm{GMM}$ estimates are computed using DPD98 for GAUSS with one-step results using heteroskedasticityconsistent standard errors and test statistics (Arellano and Bond, 1998).

First, we report some simple specifications in which we include current and lagged values of our uncertainty measures individually along with the lagged dependent variable (table 1). In particular, there are no forward-looking controls for expected future profitability in these initial models. In columns (1) and (2), we find significant negative coefficients on both current and lagged values of the stock market volatility measure as well as the measure based on the dispersion in the analysts' profits forecasts. The results in column (3) show that there are significant negative coefficients on the lagged values of the squared forecast errors $E R R_{i, t-1}$ and $E R R_{i, t-2}$, a result which suggests an inverse relationship between the variance of these recent forecast errors and investment. However, all of these results should be interpreted with caution since the Sargan tests of overidentifying restrictions indicate that our instruments are strongly rejected for these simple specifications - not surprisingly, explanatory variables other than these measures of uncertainty are required to explain company investment behavior. Nevertheless, a first

\footnotetext{
${ }^{21}$ The annual average of $V O L_{t}$ is $30 \%$ with a standard deviation of $4 \%$ and the annual average of $D I S P_{t}$ is $7 \%$ with a standard deviation of $1 \%$.

${ }^{22}$ Similar results were obtained using a range of alternative instrument sets, including, for example, lagged values of the average $q$ measures, the uncertainty measures, or sales growth.
} 
look at the estimates suggests a negative rather than a positive relationship between uncertainty and investment.

In table 2 we introduce a standard measure of Brainard-Tobin's $q\left(q_{t}^{E}\right)$, constructed using the firm's stock market valuation as a control for expected future profitability. This measure of average $q$ has a significant positive coefficient in each of the three columns, but the inclusion of this variable has little effect on the significant negative coefficients found for each of the uncertainty measures in the simpler models of table 1 . The validity of the instruments continues to be rejected at the $10 \%$ level of significance in column (1), and at the $2 \%$ level or lower in columns (2) and (3).

In table 3 we include our alternative measure of average $q\left(\hat{q}_{t}\right)$, constructed using discounted securities analysts' forecasts of the firm's future profits. This measure of average $q$ also has a significant positive coefficient in each of the three columns. Including this measure reduces the statistical significance of the coefficients on $V O L_{i, t-2}$ in column (1), $D I S P_{i, t-1}$ in column (2), and $E R R_{i, t-2}$ in column (3). Nevertheless, we continue to find a significant negative effect from each of these measures of uncertainty, a result which suggests that the effects found in tables 1 and 2 do not simply reflect higher measured uncertainty acting as a proxy for more pessimistic expectations of future profitability. We can also note that the validity of the instruments used is not rejected at any conventional level of significance by the Sargan test in the specifications reported in columns (2) and (3) of table 3.

We can further analyze the role of the various uncertainty measures by evaluating which of them is most informative, controlling for fundamentals (table 4). First, we include all three measures jointly (column 1): the negative coefficients on the current volatility and dispersion variables remain significant, but the coefficients on the squared forecast errors are now individually and jointly insignificant. This finding suggests that the significant negative effect of ERR in column (3) of the preceding tables is better captured by the other measures of uncertainty. In column (2), we drop these insignificant forecast error terms, in which case the estimated coefficients on the dispersion measure become significant at the $1 \%$ level, and those on the volatility measure become 
significant at the $10 \%$ level. However, in each case the coefficient on the lagged uncertainty measure is not significantly different from zero at the $10 \%$ level, and the same applies when we consider these coefficients on the lagged uncertainty terms jointly.

In column (3), we omit the lagged uncertainty terms which leaves us with a more parsimonious empirical specification in which dispersion-related uncertainty is highly significant and volatility-related uncertainty is marginally significant. Expected profitability as summarized by our alternative average $q$ measure has a highly significant positive effect, and the inclusion of this term is clearly important for the validity of our instruments. Furthermore, the significance of the lagged dependent variable indicates that there is more persistence in company investment rates than can be accounted for by a simple, static linear relationship with measures of uncertainty and expected future profitability. Finally, the results in column (4) show that there is no additional information in the more familiar stock-market-based $q$ given the analyst-based measure. This confirms our previous research using a different sample, although here we do find marginally significant information in one stock-market-based variable, the volatility of the firm's stock returns.

In table 5, we relax the assumption that the short- and long-run effects of uncertainty on investment have the same sign by considering nonlinear models. Part of our motivation, recalling the discussion in section 1, comes from the fact that real options models do not offer definitive predictions about the sign of uncertainty effects. We begin by noting that the coefficient on average $q$ is directly related to the speed of adjustment of the capital stock. Thus, if higher uncertainty primarily slowed the adjustment process rather than reduced the average level of the long-run capital stock, we should find a smaller coefficient on average $q$ for firms facing higher uncertainty, rather than a negative effect from our linear uncertainty terms. However, column (1) shows that we find no evidence for such an interaction effect using either of our uncertainty measures, while the coefficient on the linear dispersion term remains negative and highly significant in the presence of these interactions.

We explore the predictions of the real options literature in columns (2) and (3) by analyzing whether investment responds less to a given demand shock at higher levels of 
uncertainty. In column (2), we find that real sales growth $\left(\Delta y_{i t}\right)$ - a good measure of demand shocks given our fixed-effects formulation - is insignificant when added to the investment model which includes our analyst-based measure of $q$. This finding is consistent with our earlier results reported in Bond and Cummins (2001). However, column (3) shows that allowing for heterogeneity in the response of investment to sales growth is important. In particular, the significant negative coefficient on the interaction between sales growth and the volatility-based measure of uncertainty is evidence of a weaker short-run effect of sales growth on investment for firms that are subject to higher uncertainty. In addition, the coefficient on the linear volatility term becomes insignificantly different from zero when this interaction term is included, but the coefficient on the linear dispersion term remains negative and highly significant.

Column (4) reports our preferred parsimonious specification, which includes a significant linear term where uncertainty is measured by dispersion across analysts' forecasts of the firm's profits, and a significant interaction with sales growth, where uncertainty is measured by volatility in the firm's stock returns. Apparently, our preferred measure of average $q$ is not a sufficient statistic for company investment rates. Firms facing low levels of uncertainty increase their investment in response to a current demand shock by more than is captured by our average $q$ variable, as indicated by the negative and precisely estimated interaction term; conversely, firms facing high levels of uncertainty react less to demand shocks. Furthermore, holding constant the present discounted value of expected future profits, we find a significantly negative long-run effect of uncertainty on capital accumulation, as indicated by the negative and significant coefficient on DISP ${ }_{i t}$. Column (5) confirms that these conclusions are robust to including the stock-market-based measure of $q$, and again we find that there is no additional information relevant for explaining current investment rates in the level of the firm's stock market valuation.

\section{$\underline{4.3 \text { Short- and long-run effects of uncertainty }}$}

We can use the estimates in table 5 (column 4) to calculate the short- and long-run effects of uncertainty. In the long run, we find that a $15 \%$ increase in uncertainty-recall 
from section 4.1 that this is roughly equivalent to a one standard deviation increase in $D I S P_{t}$-is associated with a $9 \%$ reduction in the level of the capital stock, holding constant the present discounted value of the firm's expected future profits. In the short run, we find an additional effect of higher uncertainty on the relationship between investment and current demand shocks. Accounting for this, we find that a $15 \%$ increase in uncertainty — which is also equivalent to a one standard deviation increase in $\mathrm{VO}_{t}$ - is associated with a reduction in current investment rates of around $6 \%$.

It's worth reflecting on the fact that the long-run effect of uncertainty on capital accumulation is identified most clearly using a measure of uncertainty based on dispersion across different analysts' forecasts, while the short-run effect on investment dynamics is identified most clearly using a measure of uncertainty based on highfrequency stock-market volatility. Perhaps the disagreement among analysts is relatively informative about long-run prospects. Certainly we saw in figure 2 that $D I S P_{t}$ is more closely linked to business cycle dynamics. And, perhaps daily volatility is relatively informative about short-run developments that affect corporate decisions. Again, looking at figure 2, we saw that $V O L_{t}$ picks out events that might have forced firms to reevaluate investment plans, delaying or ditching them altogether. Speculation along these lines at least lines up well with the idea that analysts take the long view, on average, when forming their one- and two-year-ahead forecasts and long-term growth forecasts whereas stock market volatility reflects very high-frequency developments.

At the risk of overreaching, one might wonder whether our results help account for the behavior of business investment in the previous recession. At the aggregate level, uncertainty does not look like a very promising avenue for understanding this episode. In particular, adding measures of uncertainty to an aggregate time-series investment equation does not appreciably improve the fit of the model. However, we can use our firm-level estimates to gauge whether the effect of uncertainty on business cycle dynamics is in the right ballpark.

To create a benchmark for comparison, we estimated a simple neoclassical model for aggregate real business fixed investment (BFI) from 1975:Q1 to 2003:Q4. Specifically, we modeled the rate of BFI $(I / K)$ as a function of current and lagged values 
of the growth rates of real nonfarm business output and the user cost of capital as well as a lagged dependent variable. The aggregate time-series model misses much of the weakness in investment in the previous downturn, over predicting the investment rate in 2001 by $2.8 \%$. Seen through the lens of our firm-level estimates, however, the decline in investment is easier to rationalize. To pick a reasonable number for calibration, uncertainty - as measured by the volatility index for the S\&P 500 - rose at an annual rate of about $7 \%$ in 2001 . If we plug this $7 \%$ figure into the formula for the short-run impact of uncertainty, we would expect the investment rate in 2001 to be $3 \%$ lower as a result of increased uncertainty, about the same size as the miss in the aggregate time-series model. To be sure, it would be easy to find other periods when uncertainty exacerbated rather than mitigated the misses of the aggregate time series model. So the lesson from this exercise is that our firm-level uncertainty effects are in the right ballpark for thinking about business cycle dynamics, not that they should be used for fine-tuning macroeconomic forecasts.

\section{$\underline{4.4 \text { Alternative interpretations }}$}

As we have already stressed, we are not estimating structural parameters relating to uncertainty, so it is certainly possible to imagine alternative interpretations of our findings. In this subsection, we discuss two leading candidates. Scherbina (2001) argues that the dispersion of analysts' forecasts is related to the bias in analysts' forecasts. She notes that the consensus forecast of profits at short time horizons appears to display a greater upward bias when there is greater disagreement among the analysts that issue these forecasts for a particular firm. If this were also true at longer time horizons, the dispersion measure of uncertainty could provide an implicit bias correction to the consensus forecasts of future profits used to construct our measure of average $q$. Essentially, the concern is that the measurement error in our analyst-based measure of fundamentals could be systematically correlated with one of our uncertainty measures.

In our sample, we confirmed that there is a positive relationship between dispersion and an upward bias in the analysts' forecasts of profits for the current accounting year, but found no similar relationship between dispersion and bias in the 
analysts' forecasts of profits for the following accounting year, or in the long term growth forecasts. Despite the mixed evidence of bias in our sample, we performed an explicit robustness check by constructing a bias-corrected measure of analyst-based $q$. In particular, we bias adjusted the one- and two-year-ahead profit forecasts as well as the long-term growth forecast by taking the predicted values from a regression of realized profits (or long-term growth) on both the profit forecast (or long-term growth forecast) and our measure of dispersion. We then constructed a bias-adjusted measure of $q$ by plugging the predicted values into equation (2). The significant negative coefficient on current dispersion in our investment equations was completely robust to using biasadjusted forecasts in place of the raw analysts' forecasts when constructing our analystbased measure of $q$. Hence, it does not appear that the uncertainty effect is spuriously picking up bias in the analysts' forecasts.

As a separate but related point, we must stress that our results should not necessarily be interpreted as a rejection of the $Q$ theory of investment. In this regard, one notable disadvantage of our analyst-based measure of $q$ is the need to specify a discount factor. If we incorrectly specify the risk premium component of the firm's discount rate to be common across firms at any time, and the true variation in the risk premia used to evaluate investment decisions is correlated with one or more of our measures of uncertainty, then we could find significant coefficients on these uncertainty terms conditional on our measure of average $q$, even if firms' investment behavior is consistent with the underlying $Q$ theory of investment. Consequently, our empirical tests should not be interpreted as testing the $Q$ theory, but more narrowly as testing the null hypothesis that there are no significant effects of measured uncertainty on investment behavior, holding constant observed forecasts of future profits. This would be a major concern if the only interesting question in this context was the validity of Hayashi's $Q$ model. However, for many purposes, such as forecasting the effects of fluctuations in measures of uncertainty on business investment, it will suffice to address simpler questions concerning the relationship between uncertainty and investment at a given level of expected future profitability.

We could extend our approach in the direction of testing the $Q$ theory by incorporating some specific model of the risk premium component of the cost of capital 
into our analyst-based measure of average $q$. Indeed, we experimented with a CAPMbased firm-specific discount factor in equation (2) without affecting our basic conclusions. However, such extensions are, in our view, rather unconvincing. Certainly equating the risk premium used to evaluate investment decisions with the equity risk premium that could be estimated from the firm's stock returns appears to us to be unwarranted, given the weak relationship observed between stock market fluctuations and company investment, more generally. Of course, the same type of problem occurs when we consider using the stock-market-based measure of $q$-if share prices are noisy and our uncertainty variables are correlated with this noise, significant coefficients on the uncertainty terms conditional on Brainard-Tobin's $q$ need not imply a rejection of the underlying investment theory.

We have made some progress by investigating whether the form of any relationship between measured uncertainty and company investment is consistent with the types of predictions made by particular theories - for example, we find evidence of a weaker impact effect of demand shocks at higher levels of uncertainty predicted by the real options approach. But ultimately such findings can only be regarded as suggestive. More direct tests will need to be developed if we are to discriminate confidently between alternative theoretical explanations for the empirical relationship between uncertainty and investment that we detect using our current approach.

\section{Conclusion}

Uncertainty appears to have a strong statistical and economic impact on company investment behavior controlling for fundamentals. However, the quantitative implications should be treated with considerable caution because our preferred empirical specification is not derived from a structural analysis of the firm's investment problem. The more robust conclusion from this empirical investigation is that we reject the hypothesis that uncertainty has no effect on investment beyond that which is summarized in current expectations of future profits. And, while the results cannot be used for policy 
prescriptions, they do suggest that the effects of higher uncertainty on business investment are not at all trivial.

Nevertheless, we recognize that there may be alternative interpretations of our results. In particular, even though we find our robustness checks somewhat reassuring, both of our measures of average $q$ are subject to measurement errors that could be correlated with our measures of uncertainty. Hence, the evidence that sales growth has a weaker impact effect on investment for firms facing higher levels of uncertainty is not easy to interpret; it's consistent with one of the principal predictions of models that emphasize the role of the real option to delay investment, but it may also be rationalized within other approaches. The development of more direct tests of particular theoretical models that relate investment and uncertainty would seem to be an important topic for future research.

On a more empirical note, the approach taken in this paper could also be extended in a number of directions, in particular by considering heterogeneity in the effects of uncertainty on investment across firms with different characteristics. For example, if investment depends on uncertainty because managers are unable to fully diversify their exposure to idiosyncratic risk, along the lines suggested by Himmelberg, Hubbard and Love (2002), then we might expect the effects of uncertainty to be stronger in environments where managers are observed to have substantial equity stakes or other forms of high-powered incentive contracts. Alternatively, if the relationship between uncertainty and investment reflects the importance of real options, then we might expect these effects to be stronger in sectors where the capital has a lower resale value or where firms have more market power. Further exploration of this cross-sectional heterogeneity, along the lines initiated by Guiso and Parigi (1999), would seem to be a promising direction for future empirical work in this area. 


\section{$\underline{\text { References }}$}

Abel, A.B. (1983), “Optimal investment under uncertainty,” American Economic Review, 73, 228-233.

Abel, A.B. and Eberly, J.C. (1999), "The effects of irreversibility and uncertainty on capital accumulation," Journal of Monetary Economics, 44, 339-377.

Abel, A.B. and Eberly, J.C. (2002a), "Investment and $q$ with fixed costs: an empirical analysis," mimeo, University of Pennsylvania.

Abel, A.B. and Eberly, J.C. (2002b), " $Q$ for the long run,” mimeo, University of Pennsylvania.

Arellano, M. and Bond, S.R. (1998), "Dynamic panel data estimation using DPD98: A guide for users," mimeo, Oxford University.

Bloom, N., Bond, S.R. and Van Reenen, J. (2001), "The dynamics of investment under uncertainty," IFS Working Paper no. W01/05.

Bond, S.R. and Cummins, J.G. (2000), "The stock market and investment in the new economy: some tangible facts and intangible fictions," Brookings Papers on Economic Activity, 2000:1, 61-124.

Bond, S.R. and Cummins, J.G. (2001), "Noisy share prices and the $Q$ model of investment," IFS Working Paper no. W01/22.

Bond, S.R., Klemm, A., Newton-Smith, R., Syed, M. and Vlieghe, G. (2002), "The roles of expected profitability, Tobin's $q$ and cash flow in econometric models of company investment," mimeo, Institute for Fiscal Studies, London.

Caballero, R.J. (1991), "On the sign of the investment-uncertainty relationship," American Economic Review, 81, 271-288.

Caballero, R.J. (1999), “Aggregate investment," in Taylor, J.B. and Woodford, M. (eds), Handbook of Macroeconomics, Vol. 1B, Amsterdam: North-Holland.

Council of Economic Advisers (2004), Economic Report of the President, Washington, D.C.: U.S. Government Printing Office.

Cummins, J.G., Hassett, K.A. and Oliner, S.D. (1999), "Investment behavior, observable expectations, and internal funds," mimeo, New York University.

Dixit, A.K. and Pindyck, R.S. (1994), Investment Under Uncertainty, Princton: Princeton University Press.

Guiso, L. and Parigi, G. (1999), "Investment and demand uncertainty," Quarterly Journal of Economics, 114, 185-227.

Hartman, R.(1972), "The effects of price and cost uncertainty on investment," Journal of Economic Theory, 5, 258-266.

Hayashi, F. (1982), “Tobin's average $q$ and marginal $q$ : a neoclassical interpretation,” Econometrica, 50, 213-224. 
Himmelberg, C.P., Hubbard, R.G. and Love, I. (2002), "Investor protection, ownership, and capital allocation," mimeo, Columbia University.

Keane, Michael P. and David E. Runkle (1998), “Are financial analysts' forecasts of corporate profits rational?” Journal of Political Economy 106(4): 768-88.

Kothari, S.P. (2001), "Capital markets research in accounting," Journal of Accounting and Economics 31(1-3): 105-231.

Leahy, J.V. and Whited, T.M. (1996), "The effect of uncertainty on investment: some stylized facts," Journal of Money, Credit and Banking, 28, 64-83.

Lim, Terence (2001), "Rationality and analysts' forecast bias," Journal of Finance 56(1): 369-85.

Mankiw, N. Gregory, Ricardo Reis, and Justin Wolfers (2003), "Disagreement about Inflation Expectations," NBER working paper 9796.

Scherbina, A. (2001), "Stock prices and differences of opinion: empirical evidence that prices reflect optimism," Kellogg School of Management Finance Working Paper no. 278.

Shiller, R.J. (1981), "Do stock prices move too much to be justified by subsequent movements in dividends?" American Economic Review, 71, 421-436.

Shiller, R.J. (2000), Irrational Exuberance, Princeton University Press.

Summers, L.H. (1986), "Does the stock market rationally reflect fundamental values?" Journal of Finance, 41, 591-600.

Zarnowitz, Victor and Louis A. Lambros (1987), "Consensus and Uncertainty in Economic Prediction,” Journal of Political Economy 95(3): 591-621. 


\section{Appendix A}

To obtain the steady state partial elasticity of capital with respect to uncertainty implied by our empirical model

$$
\left(\frac{I}{K}\right)=\alpha+\beta\left(\frac{V}{\kappa}-1\right)+\gamma \sigma+\theta \Delta y+\varphi(\sigma * \Delta y)
$$

we first note that $(I / K) \approx \Delta k+\delta$, where $\Delta k$ is the growth rate of the net capital stock and $\delta$ is the depreciation rate.

Now consider a steady state in which $\Delta k=\Delta y=g$ and $\alpha=g+\delta$. Then

$$
\beta\left(\frac{V}{\kappa}-1\right)+\gamma \sigma+\theta g+\varphi \sigma g=0
$$

implying

$$
\kappa=f(\sigma) V
$$

with

$$
f(\sigma)=\left[1-\left(\frac{\gamma+\varphi g}{\beta}\right) \sigma-\left(\frac{\theta}{\beta}\right) g\right]^{-1}
$$

In this case,

$$
\begin{aligned}
\left.\frac{\partial \kappa}{\partial \sigma} \cdot \frac{\sigma}{\kappa}\right|_{V} & =\left(\frac{V}{\kappa}\right) \sigma f^{\prime}(\sigma) \\
& =\left(\frac{V}{\kappa}\right)\left\{\frac{\left(\frac{\gamma+\varphi g}{\beta}\right) \sigma}{\left[1-\left(\frac{\gamma+\varphi g}{\beta}\right) \sigma-\left(\frac{\theta}{\beta}\right) g\right]^{2}}\right\} .
\end{aligned}
$$


Figure 1: Relationships between firm-specific uncertainty measures
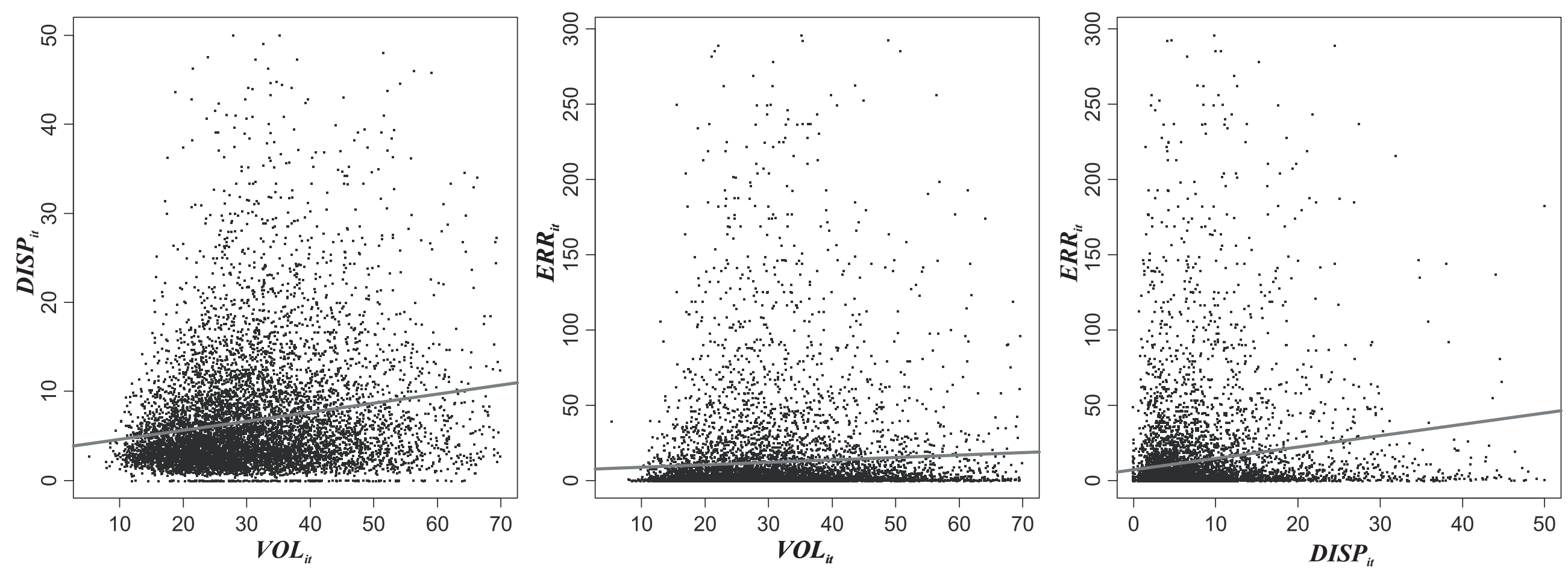

Note. Data are in percent. The OLS regression line is depicted in grey.

Source. Authors' calculations based on Compustat and I/B/E/S data. 


\section{Figure 2: Uncertainty measures - time-series variation}

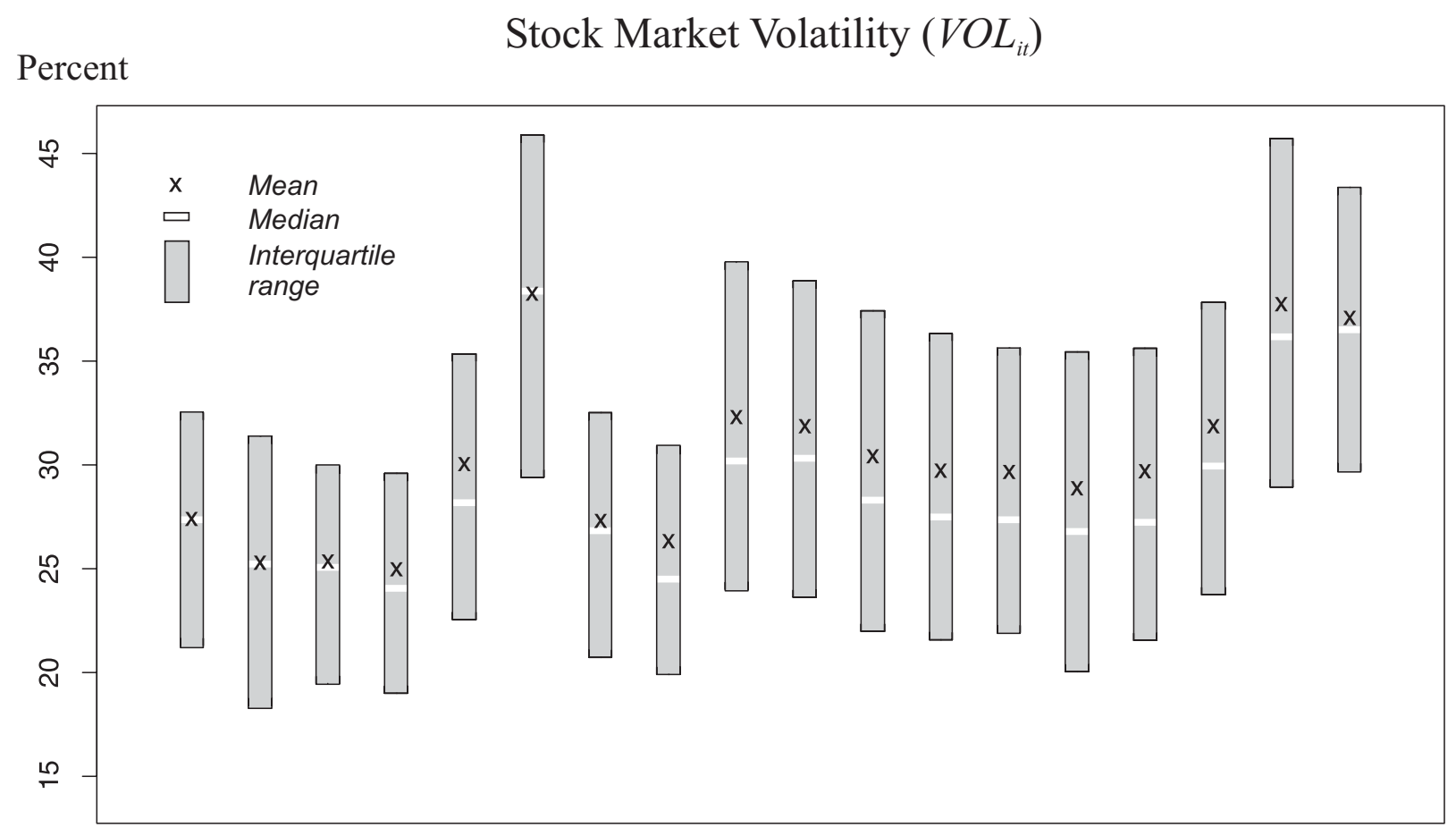

198219831984198519861987198819891990199119921993199419951996199719981999

Dispersion of Analysts' Forecasts $\left(D I S P_{i t}\right)$

Percent

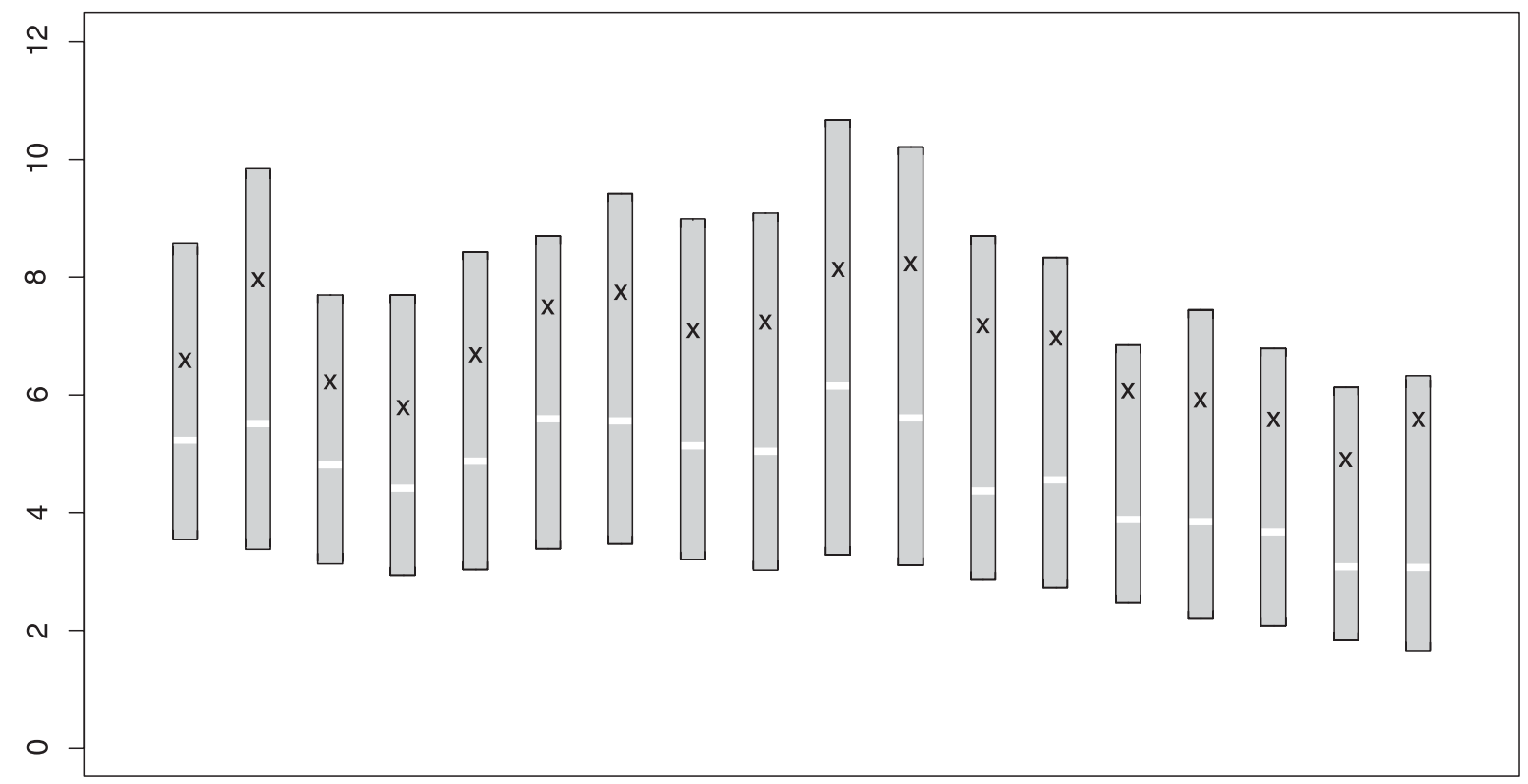

198219831984198519861987198819891990199119921993199419951996199719981999

Source. Authors' calculations based on Compustat and I/B/E/S data. 
Table 1: Relationship between investment and uncertainty measures, 1985-99

\begin{tabular}{|c|c|c|c|}
\hline & (1) & $(2)$ & $(3)$ \\
\hline$V O L_{i t}$ & $\begin{array}{l}-0.338 \\
(0.117)\end{array}$ & - & - \\
\hline$V O L_{i, t-1}$ & $\begin{array}{l}-0.420 \\
(0.114)\end{array}$ & - & - \\
\hline$V O L_{i, t-2}$ & $\begin{array}{l}-0.239 \\
(0.121)\end{array}$ & - & - \\
\hline$D I S P_{i t}$ & - & $\begin{array}{l}-0.613 \\
(0.142)\end{array}$ & - \\
\hline$D I S P_{i, t-1}$ & - & $\begin{array}{l}-0.298 \\
(0.107)\end{array}$ & - \\
\hline$D I S P_{i, t-2}$ & - & $\begin{array}{l}-0.013 \\
(0.138)\end{array}$ & - \\
\hline$E R R_{i t}$ & - & - & $\begin{array}{l}-0.014 \\
(0.027)\end{array}$ \\
\hline$E R R_{i, t-1}$ & - & - & $\begin{array}{l}-0.075 \\
(0.021)\end{array}$ \\
\hline$E R R_{i, t-2}$ & - & - & $\begin{array}{l}-0.063 \\
(0.017)\end{array}$ \\
\hline \multirow[t]{2}{*}{$(I / K)_{i, t-1}$} & $\begin{array}{c}0.286 \\
(0.035)\end{array}$ & $\begin{array}{c}0.272 \\
(0.034)\end{array}$ & $\begin{array}{c}0.306 \\
(0.033)\end{array}$ \\
\hline & \multicolumn{3}{|c|}{ Diagnostic Tests } \\
\hline Serial correlation ${ }^{1}$ & & & \\
\hline First-order & -8.32 & -10.0 & -10.3 \\
\hline Second-order & -0.15 & -0.10 & -0.24 \\
\hline Sargan test ${ }^{2}$ & 0.022 & 0.006 & 0.004 \\
\hline $\begin{array}{l}\text { Joint significance }^{3} \\
\text { uncertainty measures }\end{array}$ & 0.001 & 0.000 & 0.001 \\
\hline
\end{tabular}

Note. In this and subsequent tables, as well as in the charts, the sample contains firms with at least four years of complete data; $N=946$, for a total of 5,814 observations. The dependent variable is $(I / K)_{i t}$. The measure of volatility, $V O L_{i t}$, is the standard deviation of daily stock returns during the firm's current accounting year. The measure of dispersion, $D I S P_{i t}$, is the coefficient of variation across different analysts' forecasts of earnings per share for the firm's current accounting period. The measure of the forecast error, $E R R_{i t}$, is the square of the difference between the consensus forecasts of earnings per share and the realized level of earnings per share for the firm's current accounting period. Estimation is in first-differences to remove unobserved firm-specific effects. Time dummies are included (but not reported) in all specifications. All right-hand-side variables are treated as endogenous. The instrumental variables used in all specifications are $(I / K)_{i, t-2},(I / K)_{i, t-3},(C F / K)_{i, t-2}$, and $(C F / K)_{i, t-3}$, Estimates are computed using DPD98 for GAUSS. One-step coefficients with heteroskedasticity consistent standard errors reported in parentheses.

1. The test for serial correlation in the first-differenced residuals is asymptotically distributed as $\mathrm{N}(0,1)$ under the null of no serial correlation.

2. The test of the overidentifying restrictions, called a Sargan test, is asymptotically distributed as $\chi_{(n-p)}^{2}$, where $n$ is the number of instruments and $p$ is the number of parameters. We report $p$-values, that is the probability of obtaining the recorded value of the statistic if the null hypothesis of valid moment conditions is correct.

3. Joint significance statistics are $p$-values from the Wald test that the coefficients are equal to zero on the indicated sets of explanatory variables. 
Table 2: Relationship between investment and uncertainty measures, controlling for stock-market-based $q$, 1985-99

\begin{tabular}{|c|c|c|c|}
\hline & (1) & $(2)$ & (3) \\
\hline$V O L_{i t}$ & $\begin{array}{l}-0.319 \\
(0.113)\end{array}$ & - & - \\
\hline$V O L_{i, t-1}$ & $\begin{array}{l}-0.505 \\
(0.122)\end{array}$ & - & - \\
\hline$V O L_{i, t-2}$ & $\begin{array}{l}-0.287 \\
(0.121)\end{array}$ & - & - \\
\hline$D I S P_{i t}$ & - & $\begin{array}{l}-0.683 \\
(0.144)\end{array}$ & - \\
\hline$D I S P_{i, t-1}$ & - & $\begin{array}{l}-0.257 \\
(0.111)\end{array}$ & - \\
\hline$D I S P_{i, t-2}$ & - & $\begin{array}{c}0.017 \\
(0.135)\end{array}$ & - \\
\hline$E R R_{i t}$ & - & - & $\begin{array}{l}-0.029 \\
(0.027)\end{array}$ \\
\hline$E R R_{i, t-1}$ & - & - & $\begin{array}{l}-0.086 \\
(0.021)\end{array}$ \\
\hline$E R R_{i, t-2}$ & - & - & $\begin{array}{l}-0.050 \\
(0.018)\end{array}$ \\
\hline$q_{i t}^{E}$ & $\begin{array}{c}0.021 \\
(0.005)\end{array}$ & $\begin{array}{c}0.019 \\
(0.005)\end{array}$ & $\begin{array}{c}0.019 \\
(0.005)\end{array}$ \\
\hline \multirow[t]{2}{*}{$(I / K)_{i, t-1}$} & $\begin{array}{c}0.227 \\
(0.037)\end{array}$ & $\begin{array}{c}0.228 \\
(0.035)\end{array}$ & $\begin{array}{c}0.263 \\
(0.031)\end{array}$ \\
\hline & \multicolumn{3}{|c|}{ Diagnostic Tests } \\
\hline Serial correlation & & & \\
\hline First-order & -7.00 & -9.08 & -9.75 \\
\hline Second-order & -0.95 & -0.28 & -0.58 \\
\hline Sargan test & 0.089 & 0.020 & 0.004 \\
\hline $\begin{array}{l}\text { Joint significance } \\
\text { uncertainty measures }\end{array}$ & 0.000 & 0.000 & 0.000 \\
\hline
\end{tabular}

Note. The measure of fundamentals, $q_{i t}^{E}$, is based on stock-market data. See also notes to table 1 . 
Table 3: Relationship between investment and uncertainty measures, controlling for analyst-based $q, 1985-99$

\begin{tabular}{|c|c|c|c|}
\hline & (1) & $(2)$ & $(3)$ \\
\hline$V O L_{i t}$ & $\begin{array}{l}-0.293 \\
(0.111)\end{array}$ & - & - \\
\hline$V O L_{i, t-1}$ & $\begin{array}{l}-0.308 \\
(0.109)\end{array}$ & - & - \\
\hline$V O L_{i, t-2}$ & $\begin{array}{l}-0.152 \\
(0.115)\end{array}$ & - & - \\
\hline$D I S P_{i t}$ & - & $\begin{array}{l}-0.600 \\
(0.153)\end{array}$ & - \\
\hline$D I S P_{i, t-1}$ & - & $\begin{array}{l}-0.194 \\
(0.128)\end{array}$ & - \\
\hline$D I S P_{i, t-2}$ & - & $\begin{array}{c}0.050 \\
(0.136)\end{array}$ & - \\
\hline$E R R_{i t}$ & - & - & $\begin{array}{l}-0.034 \\
(0.027)\end{array}$ \\
\hline$E R R_{i, t-1}$ & - & - & $\begin{array}{l}-0.078 \\
(0.023)\end{array}$ \\
\hline$E R R_{i, t-2}$ & - & - & $\begin{array}{l}-0.042 \\
(0.020)\end{array}$ \\
\hline$\hat{q}_{i t}$ & $\begin{array}{c}0.067 \\
(0.014)\end{array}$ & $\begin{array}{c}0.073 \\
(0.015)\end{array}$ & $\begin{array}{c}0.079 \\
(0.016)\end{array}$ \\
\hline \multirow[t]{2}{*}{$(I / K)_{i, t-1}$} & $\begin{array}{c}0.223 \\
(0.036)\end{array}$ & $\begin{array}{c}0.203 \\
(0.038)\end{array}$ & $\begin{array}{c}0.222 \\
(0.035)\end{array}$ \\
\hline & \multicolumn{3}{|c|}{ Diagnostic Tests } \\
\hline Serial correlation & & & \\
\hline First-order & -9.08 & -8.57 & -9.19 \\
\hline Second-order & 0.14 & -0.25 & -0.64 \\
\hline Sargan test & 0.098 & 0.268 & 0.184 \\
\hline $\begin{array}{l}\text { Joint significance } \\
\text { uncertainty measures }\end{array}$ & 0.012 & 0.001 & 0.005 \\
\hline
\end{tabular}

Note. The measure of fundamentals, $\hat{q}_{i t}$, is based on analysts' profit forecasts. See also notes to table 1. 
Table 4: Combining measures of uncertainty and fundamentals, 1985-99

\begin{tabular}{|c|c|c|c|c|}
\hline & (1) & (2) & (3) & (4) \\
\hline$V O L_{i t}$ & $\begin{array}{c}-0.232 \\
(0.110)\end{array}$ & $\begin{array}{l}-0.236 \\
(0.111)\end{array}$ & $\begin{array}{c}-0.221 \\
(0.110)\end{array}$ & $\begin{array}{l}-0.210 \\
(0.110)\end{array}$ \\
\hline$V O L_{i, t-1}$ & $\begin{array}{l}-0.161 \\
(0.117)\end{array}$ & $\begin{array}{l}-0.155 \\
(0.117)\end{array}$ & - & - \\
\hline$D I S P_{i t}$ & $\begin{array}{l}-0.398 \\
(0.207)\end{array}$ & $\begin{array}{l}-0.556 \\
(0.166)\end{array}$ & $\begin{array}{c}-0.584 \\
(0.155)\end{array}$ & $\begin{array}{l}-0.606 \\
(0.158)\end{array}$ \\
\hline$D I S P_{i, t-1}$ & $\begin{array}{l}-0.173 \\
(0.164)\end{array}$ & $\begin{array}{l}-0.182 \\
(0.129)\end{array}$ & - & - \\
\hline$E R R_{i t}$ & $\begin{array}{c}-0.038 \\
(0.031)\end{array}$ & - & - & - \\
\hline$E R R_{i, t-1}$ & $\begin{array}{l}-0.015 \\
(0.025)\end{array}$ & - & - & - \\
\hline$\hat{q}_{i t}$ & $\begin{array}{c}0.069 \\
(0.016)\end{array}$ & $\begin{array}{c}0.068 \\
(0.015)\end{array}$ & $\begin{array}{c}0.077 \\
(0.014)\end{array}$ & $\begin{array}{c}0.069 \\
(0.016)\end{array}$ \\
\hline$(I / K)_{i, t-1}$ & $\begin{array}{c}0.201 \\
(0.038)\end{array}$ & $\begin{array}{c}0.199 \\
(0.038)\end{array}$ & $\begin{array}{c}0.215 \\
(0.037)\end{array}$ & $\begin{array}{c}0.209 \\
(0.037)\end{array}$ \\
\hline$q_{i t}^{E}$ & - & - & - & $\begin{array}{c}0.006 \\
(0.006)\end{array}$ \\
\hline & \multicolumn{4}{|c|}{ Diagnostic Tests } \\
\hline \multicolumn{5}{|l|}{ Serial correlation } \\
\hline First-order & -7.95 & -7.61 & -10.2 & -10.1 \\
\hline Second-order & -0.43 & -0.36 & 0.92 & 0.93 \\
\hline Sargan test & 0.443 & 0.520 & 0.611 & 0.555 \\
\hline \multicolumn{5}{|l|}{ Joint significance } \\
\hline$V O L_{i t}, V O L_{i, t-1}$ & 0.078 & 0.082 & - & - \\
\hline$D I S P_{i t}, D I S P_{i, t-1}$ & 0.139 & 0.004 & - & - \\
\hline$E R R_{i t}, E R R_{i, t-1}$ & 0.489 & - & - & - \\
\hline$V O L_{i, t-1}, D I S P_{i, t-1}$ & - & 0.144 & - & - \\
\hline
\end{tabular}

Note. See notes to tables 1,2 and 3 . 
Table 5: Nonlinear models of the relationship between investment and uncertainty, 1985-99

\begin{tabular}{|c|c|c|c|c|c|}
\hline & (1) & $(2)$ & $(3)$ & (4) & $(5)$ \\
\hline$V O L_{i t}$ & $\begin{array}{l}-0.137 \\
(0.134)\end{array}$ & $\begin{array}{l}-0.217 \\
(0.111)\end{array}$ & $\begin{array}{l}-0.111 \\
(0.134)\end{array}$ & - & - \\
\hline$D I S P_{i t}$ & $\begin{array}{l}-0.795 \\
(0.246)\end{array}$ & $\begin{array}{l}-0.590 \\
(0.155)\end{array}$ & $\begin{array}{l}-0.587 \\
(0.170)\end{array}$ & $\begin{array}{l}-0.619 \\
(0.164)\end{array}$ & $\begin{array}{l}-0.638 \\
(0.167)\end{array}$ \\
\hline$V O L_{i t} * \hat{q}_{i t}$ & $\begin{array}{l}-0.039 \\
(0.033)\end{array}$ & - & - & - & - \\
\hline$D I S P_{i t} * \hat{q}_{i t}$ & $\begin{array}{c}0.233 \\
(0.167)\end{array}$ & - & - & - & - \\
\hline$V O L_{i t} * \Delta y_{i t}$ & - & - & $\begin{array}{l}-1.08 \\
(0.497)\end{array}$ & $\begin{array}{l}-1.24 \\
(0.420)\end{array}$ & $\begin{array}{l}-1.20 \\
(0.419)\end{array}$ \\
\hline$D I S P_{i t} * \Delta y_{i t}$ & - & - & $\begin{array}{l}-0.733 \\
(0.763)\end{array}$ & - & - \\
\hline$\hat{q}_{i t}$ & $\begin{array}{c}0.084 \\
(0.017)\end{array}$ & $\begin{array}{c}0.076 \\
(0.014)\end{array}$ & $\begin{array}{c}0.076 \\
(0.015)\end{array}$ & $\begin{array}{c}0.079 \\
(0.015)\end{array}$ & $\begin{array}{c}0.072 \\
(0.018)\end{array}$ \\
\hline$(I / K)_{i, t-1}$ & $\begin{array}{c}0.201 \\
(0.039)\end{array}$ & $\begin{array}{c}0.227 \\
(0.042)\end{array}$ & $\begin{array}{c}0.215 \\
(0.043)\end{array}$ & $\begin{array}{c}0.214 \\
(0.043)\end{array}$ & $\begin{array}{c}0.210 \\
(0.043)\end{array}$ \\
\hline$\Delta y_{i t}$ & - & $\begin{array}{c}-0.032 \\
(0.051)\end{array}$ & $\begin{array}{c}0.431 \\
(0.195)\end{array}$ & $\begin{array}{c}0.420 \\
(0.158)\end{array}$ & $\begin{array}{c}0.404 \\
(0.159)\end{array}$ \\
\hline$q_{i t}^{E}$ & - & - & - & - & $\begin{array}{c}0.005 \\
(0.006)\end{array}$ \\
\hline & \multicolumn{5}{|c|}{ Diagnostic Tests } \\
\hline Serial correlation & & & & & \\
\hline First-order & -10.2 & -9.87 & -9.61 & -9.79 & -9.74 \\
\hline Second-order & -0.63 & 0.88 & 0.14 & 0.10 & 0.17 \\
\hline Sargan test & 0.652 & 0.611 & 0.708 & 0.536 & 0.529 \\
\hline $\begin{array}{l}\text { Joint significance } \\
\quad \text { Nonlinear interaction terms }\end{array}$ & 0.319 & - & 0.064 & - & - \\
\hline
\end{tabular}

Note. See notes to tables 1, 2 and 3 . 